\title{
The Suggested Correlation Formula between (HPF) and (OPMUF) Parameters over Middle East Region
}

\author{
Khalid A. Hadi ${ }^{1}$, Aqeel Z. Aziz ${ }^{2}$ \\ ${ }^{1,2}$ (Department of Astronomy \& Space, College of Sciences, University of Baghdad, Baghdad - Iraq)
}

\begin{abstract}
In this project, a study of the behavior and correlation between High Possible Frequency (HPF) and Optimum Maximum Usable Frequency (OPMUF) parameters for the communication links distributed over Middle East Region were made. A mutual correlation equation between the two parameters has been suggested. The analytical test of the monthly and annual variation of the (HPF) and (OPMUF) parameters have been conducted for the gathered theoretical dataset which calculated using the VOACAP and REC533 international $H F$ models for the solar activity year of 2000. According to the results of this test, the correlation between the two parameters is simple and can be expressed by a linear regression formula. The predicted values using the suggested equation gave a good fitting with the theoretical values generated from the international HFcommunication models.
\end{abstract}

Key words- High Possible Frequency (HPF), Ionospheric parameters, Optimum Maximum Usable Frequency (OPMUF), Radio wave propagation.

\section{Introduction}

The ionosphere is represented one of the regions of the Earth's atmosphere which is extended approximately from 60 to $1000 \mathrm{~km}$. this region is formed by interaction of solar radiation with uncharged particles of uppermost part of earth's atmosphere resulting ions and electrons. The ionosphere layer is depending on the electron density, so this layer is subdivided into four layers: D-layer (60 to $90 \mathrm{~km}$ ), E and $\mathrm{E}_{\mathrm{s}}$ layers (90 to $140 \mathrm{~km}$ ), F1 and F2 layers (140 to $420 \mathrm{~km}$ ) and Topside layer (420 to 1000) [1].

The Highest Possible Frequency (HPF) and Optimum Maximum Usable Frequency (OPMUF) are two of the ionospheric parameters. The (HPF) is defined as "the highest possible frequency can be reflected from the ionosphere layer". It is working the upper usable limit exceeded 3 days per month. The (OPMUF) is defined as "the effective optimum maximum usable frequency can be reflected from the ionospheric layer".

As these parameters strongly depends on the ionization level of the F-layer, so the values of these parameters increases at strong solar activity and conversely occurs at week solar activity the ionospheric parameters values decreases [2].The HPF \& OPMUF are important to determine the best highest frequency that used to maintain the link between two locations.

Many experiments were made from number of researchers to studying the ionospheric parameters like Lincoln and Godley Head [1960], Jones M. R. and Stephenson J. J.[1975], Bröms M. and B. Lundborg [1994] [3], Obrou 0. K. [2003], Olga A. Maltseva [2006], Chunxu Liu [2008] [4], Jian Wang [2010] [3] and Michael Warrington [2012] [4].

In this research, the correlation relation between HPF and OPMUF has been studied for maximum solar activity of solar cycle 23 over Middle East region.

\section{Radio Communications}

Radio waves are electromagnetic waves that have rang of frequency from $3 \mathrm{~Hz}$ to $300 \mathrm{GHz}$. Most modern communication used the propagation of radio waves through the ionosphere especially the earliest form of radio communication used High Frequency (HF) (3-30) which are experimented by Hertz and Marconi [5].

Ionosphere layer is considered an important layer for reflection HF band to the surface of the earth. The most technique used for propagation of HF signals through ionosphere layer from point to point is known as sky wave propagation which is also used for many purposes like civil and military and other uses.

The HF radio communication for long distance is utilized sky waves technique because these waves are affected by ionized layer at least three ways [6].

Firstly under suitable conditions, the energy of sky waves is absorbed by charge particles, causing attenuation for these waves. Secondly due to the randomly distribution of electron density in ionosphere layer is lead to change the direction of sky waves traveling from one place to another. Thirdly occasionally the sky waves have ability to penetrate ionosphere layer, because these waves have enough energy to penetrate ionosphere layer [7], as shown in figure (1). 


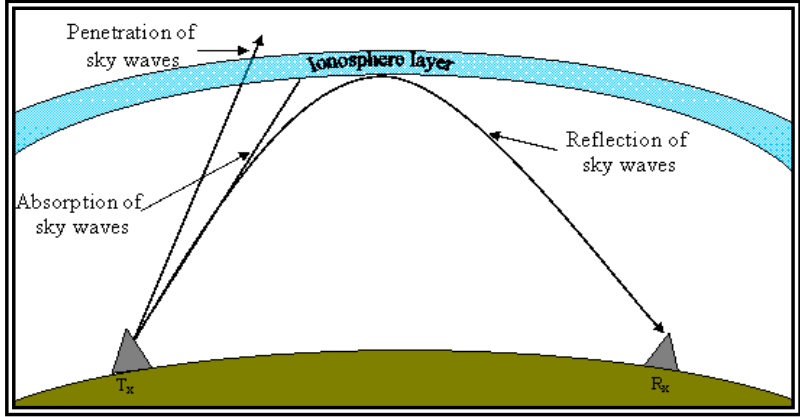

Fig. 1. Illustrates the propagation of sky waves [7].

The International Telecommunications Union (ITU) was established many international standard models for ionospheric characteristics. On advice from its International Radio Consultative Committee (CCIR) and, more recently, it's Radio Communication Sector (ITU-R) has issued a standard set of models like CCIR [1966 - 1991], ITU-R [1997] and other. The CCIR models and related software are released by ITU [8]. Most HF communication models intended for direct reception from large number of public broadcasting stations which are also known as "world band radio", because these models used analog modulation techniques which is employed for broadcasting in HF band.

\section{HF International Communication Models}

In this project, the "VOACAP" and "REC533" international HF communication models has been adopted to predict the expected performance of high frequency band. Most of broadcasting stations in the world (British Broadcasting Corporation (BBC), United State International Broadcasting (USIB) and others) use VOACAP and REC533 models because these models represent last and best models to analysis HF band.

In 1985, the broadcasting of Voice of America (VOA) was utilized the Ionospheric Communications Analysis and Prediction Program (IONCAP) which is represented the first professional ionospheric signal model. The name of this program was changed to the Voice of America Coverage Analysis Program (VOACAP) in order to distinguish it from the official "National Telecommunications and Information Administration" (NTIA) of "IONCAP" program. The development of VOACAP was accomplished by the Naval Research Laboratory (NRL) and Institute for Telecommunication Sciences (ITS) [9]. The Recommendation 533 model (REC533) was released by the ITU in July 1993 by Working Party 6A (WP6A). It was developed and was maintained by the United States, Department of Commerce, National Telecommunications and Information Administration, Institute for Telecommunication Sciences (NTIA/ITS) [10]. VOACAP and REC533 models were design to measure the characteristics of ionosphere and to analysis the range of $\mathrm{HF}$ band for a specified path between a transmitter and a receiver stations.

\section{Test And Results}

The aim of this research is to study the behavior and correlation between High Possible Frequency (HPF) and Optimum Maximum Usable Frequency (OPMUF) parameters for the communication links between the transmitting and receiving stations over Middle East Region. The year of 2000 has been adopted to be a year of study, because the selected year represents a maximum active cycle of the solar cycle 23 . The monthly sunspot numbers of the selected year are shown in table (1):

Table 1 Shows the monthly sunspot number of the year 2000.

\begin{tabular}{|c|c|}
\hline Month Name & $\begin{array}{c}\text { Sunspot Numbers } \\
\text { (SSNs) }\end{array}$ \\
\hline Jan & 90.1 \\
\hline Feb & 112.9 \\
\hline Mar & 138.5 \\
\hline Apr & 125.5 \\
\hline May & 121.6 \\
\hline Jun & 124.9 \\
\hline July & 170.1 \\
\hline Aug & 130.1 \\
\hline Sep & 109.7 \\
\hline Oct & 99.4 \\
\hline Nov & 106.8 \\
\hline Dec & 104.4 \\
\hline
\end{tabular}


The Middle East Region has been adopted to be the region of study, so the capital Baghdad was considered as a transmitting station while other thirty five different locations which are spreading around Baghdad city have been considered as receiving stations, as shown in figure (2):-

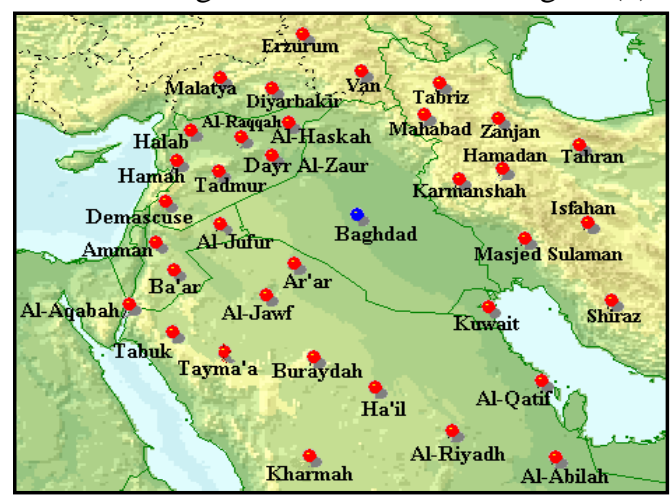

Fig. 2. Show the selected receiving stations around the capital Baghdad (Transmitting station).

The geographical locations (Latitude and Longitude) and distance of the selected receiving stations are listed in table (2):-

Table 2 Show Latitude, Longitude and distance of the receiving stations.

\begin{tabular}{|l|c|c|c|}
\hline \multirow{2}{*}{ Station Name } & \multicolumn{2}{|c|}{ Geographical location } & \multirow{2}{*}{$\begin{array}{c}\text { Distance } \\
\text { (Km) }\end{array}$} \\
\cline { 2 - 3 } & $\begin{array}{c}\text { Latitude } \\
(\mathbf{N})\end{array}$ & $\begin{array}{c}\text { Longitude } \\
\text { (E) }\end{array}$ & \\
\hline Al-Abilah & 23.5 & 50.43 & 1244.2 \\
\hline Al-Aqabah & 29.25 & 35 & 985.9 \\
\hline Halab & 36.20 & 37.17 & 730.5 \\
\hline Al-Hazakah & 36.48 & 40.75 & 480.2 \\
\hline Al-Jawf & 29.86 & 39.87 & 576.9 \\
\hline Al-Jufur & 32.53 & 38.23 & 580.9 \\
\hline Al-Qatif & 26.93 & 50 & 894.8 \\
\hline Al-Raqqah & 35.93 & 39.02 & 567.9 \\
\hline Amman & 31.95 & 35.93 & 806 \\
\hline Ar'ar & 30.95 & 41 & 415.2 \\
\hline Ba'ar & 30.78 & 36.68 & 779.6 \\
\hline Buraydah & 26.33 & 43.98 & 781.5 \\
\hline Dayr Alzawr & 35.33 & 40.15 & 446.3 \\
\hline Demascuse & 33.5 & 36.25 & 754.5 \\
\hline Diyarbakir & 37.91 & 40.24 & 630 \\
\hline Erzurum & 39.92 & 41.28 & 781 \\
\hline Ha'il & 27.55 & 41.7 & 694 \\
\hline Hamadan & 34.8 & 48.5 & 412.3 \\
\hline Hamah & 35.13 & 36.75 & 728.5 \\
\hline Isfahan & 32.67 & 51.63 & 680.1 \\
\hline Karmanshah & 34.32 & 47.07 & 270 \\
\hline Kharma & 23.61 & 41.4 & 1221.3 \\
\hline Kuwait & 29.33 & 47.98 & 562.7 \\
\hline Mahabad & 36.72 & 45.70 & 393.5 \\
\hline Malatya & 38.35 & 38.32 & 779 \\
\hline Masjed Sul. & 31.98 & 49.51 & 503.6 \\
\hline Riyadh & 24.63 & 46.72 & 995.9 \\
\hline Shiraz & 29.6 & 52.53 & 877.8 \\
\hline Tabriz & 30.08 & 46.3 & 553.7 \\
\hline Tabuk & 28.38 & 36.58 & 926.7 \\
\hline Tadmur & 34.6 & 38.25 & 581.9 \\
\hline Tayma'a & 27.5 & 38.48 & 1053.1 \\
\hline Tahran & 38.55 & 43.36 & 585.4 \\
\hline Van & 48.49 & 526.4 \\
\hline Zanjan & & \\
\hline & & & \\
\hline & 36.63 & & \\
\hline
\end{tabular}


In this research the international communication model "VOACAP" has been used to calculate the dataset of the HPF parameter, while the dataset of the OPMUF parameter has been determined using the "REC533" international communication model.

Table (3), shows samples of the output dataset of the (OPMUF) \& (HPF) parameters from the execution of the picked international models for the link (Baghdad - Van).

Table 3 Shows samples of the dataset of the (OPMUF) \& (HPF) parameters.

\begin{tabular}{|c|c|c|c|c|c|c|c|c|c|c|c|c|}
\hline \multicolumn{10}{|c|}{ (Baghdad- Van) } \\
\hline Time & Jan. & Feb. & Mar. & Apr. & May & Jun. & July & Aug. & Sep. & Oct. & Nov. & Dec. \\
\hline 0 & 6.7 & 8.4 & 11.3 & 12.9 & 12.8 & 12.7 & 13.1 & 11.3 & 10.3 & 9 & 8.3 & 7.3 \\
\hline 1 & 7 & 8.4 & 11 & 12.5 & 12.4 & 12.2 & 12.6 & 11.1 & 10 & 9 & 8.5 & 7.5 \\
\hline 2 & 7.4 & 8.6 & 10.6 & 11.9 & 11.9 & 11.5 & 12.1 & 10.7 & 9.7 & 8.9 & 8.7 & 7.7 \\
\hline 3 & 7.2 & 8.4 & 9.9 & 11.1 & 11.4 & 10.9 & 11.4 & 10.1 & 9.2 & 8.4 & 8.2 & 7.3 \\
\hline 4 & 6.3 & 7.4 & 9 & 10.5 & 11.1 & 9.8 & 10.1 & 9.8 & 8.6 & 7.7 & 7.3 & 6.3 \\
\hline 5 & 5.6 & 6.7 & 8.8 & 10 & 10.6 & 10.2 & 10.5 & 9.4 & 9.1 & 8 & 7.2 & 5.9 \\
\hline 6 & 5.8 & 7.2 & 9.6 & 11.5 & 11.6 & 11.2 & 11.6 & 10.7 & 10.2 & 9.4 & 9 & 7.2 \\
\hline 7 & 8.1 & 10.2 & 12.6 & 13.6 & 12.8 & 12.1 & 12.5 & 12 & 12.6 & 12.4 & 11.7 & 9.5 \\
\hline 8 & 11.5 & 14 & 15.9 & 15.5 & 13.5 & 12.4 & 12.6 & 12.7 & 14.2 & 15 & 15.2 & 12.9 \\
\hline 9 & 14.6 & 16.9 & 18.1 & 16.6 & 13.8 & 12.4 & 12.4 & 12.7 & 14.8 & 16.4 & 17.6 & 15.6 \\
\hline 10 & 16.3 & 18.1 & 18.9 & 17.3 & 14 & 12.5 & 12.6 & 13 & 15 & 16.9 & 18 & 17 \\
\hline 11 & 16.4 & 18.3 & 19.2 & 18.1 & 14.7 & 13 & 13.3 & 13.7 & 15.3 & 16.9 & 18.3 & 17.2 \\
\hline 12 & 15.8 & 18 & 19.3 & 18.8 & 15.5 & 13.6 & 14 & 14.4 & 15.5 & 16.7 & 17.9 & 16.4 \\
\hline 13 & 15.4 & 17.8 & 19.1 & 19 & 15.9 & 13.9 & 14.5 & 14.6 & 15.5 & 16.6 & 17.6 & 15.5 \\
\hline 14 & 15.2 & 17.6 & 18.6 & 18.6 & 15.7 & 13.7 & 14.5 & 14.4 & 15.4 & 16.6 & 17.4 & 15.1 \\
\hline 15 & 14.9 & 17.6 & 18.2 & 18.1 & 15.3 & 13.3 & 14.1 & 14.1 & 15.3 & 16.6 & 17.3 & 14.9 \\
\hline 16 & 14.2 & 17.4 & 17.9 & 17.7 & 14.9 & 12.9 & 13.6 & 13.8 & 15 & 16.3 & 16.6 & 14.5 \\
\hline 17 & 12.9 & 16.6 & 17.3 & 17.3 & 14.5 & 12.9 & 13.4 & 13.5 & 14.5 & 15.3 & 15.2 & 13.2 \\
\hline 18 & 12.1 & 14 & 15.9 & 16.3 & 14.1 & 12.7 & 13.3 & 13.1 & 13.6 & 13.7 & 13.1 & 11.5 \\
\hline 19 & 10.1 & 13.5 & 15.5 & 15 & 13.4 & 12.4 & 13 & 12.7 & 12.5 & 13 & 12 & 10.7 \\
\hline 20 & 8.3 & 11.2 & 13.9 & 14.9 & 12.6 & 11.9 & 12.5 & 13.2 & 12.3 & 11.3 & 10.4 & 9.4 \\
\hline 21 & 7.3 & 9.7 & 12.9 & 14.1 & 13.3 & 12.7 & 13.4 & 12.5 & 11.5 & 10.1 & 9.5 & 8.5 \\
\hline 22 & 6.9 & 9 & 12.1 & 13.6 & 13.1 & 12.8 & 13.5 & 11.9 & 10.9 & 9.5 & 8.9 & 7.9 \\
\hline 23 & 6.7 & 8.6 & 11.6 & 13.3 & 13 & 12.9 & 13.4 & 11.6 & 10.6 & 9.2 & 8.5 & 7.5 \\
\hline
\end{tabular}

\begin{tabular}{|c|c|c|c|c|c|c|c|c|c|c|c|c|}
\hline \multicolumn{10}{|c|}{ HPF (VOACAP) } \\
\hline Time & Jan. & Feb. & Mar. & Apr. & May & Jun. & July & Aug. & Sep. & Oct. & Nov. & Dec. \\
\hline 0 & 6.41 & 7.16 & 9.92 & 11.4 & 11.7 & 11.5 & 12.5 & 10.3 & 9.08 & 8.5 & 7.12 & 6.32 \\
\hline 1 & 6.73 & 7.22 & 9.67 & 11 & 11.35 & 11 & 12.1 & 10 & 8.9 & 8.48 & 7.28 & 6.47 \\
\hline 2 & 6.54 & 7.34 & 9.43 & 10.5 & 10.97 & 10.4 & 11.6 & 9.67 & 8.71 & 7.99 & 7.5 & 6.58 \\
\hline 3 & 6.35 & 7.12 & 8.79 & 9.83 & 10.48 & 9.86 & 11 & 9.2 & 8.18 & 7.52 & 7.13 & 6.25 \\
\hline 4 & $\mathbf{5 . 5 6}$ & 6.33 & 8.02 & 9.35 & 10.21 & 9.6 & 10.6 & 8.9 & 7.73 & 6.92 & 6.36 & 5.44 \\
\hline 5 & 4.94 & $\mathbf{5 . 7 5}$ & 7.84 & 9.62 & 10.54 & 9.98 & 10.9 & 9.27 & 8.15 & 7.2 & 6.24 & 5.08 \\
\hline 6 & $\mathbf{5 . 2 7}$ & 6.54 & 9.24 & 11.1 & 11.62 & 12.4 & 13.6 & 11.9 & 9.9 & 9.08 & 7.85 & 6.08 \\
\hline 7 & 7.29 & 9.13 & 12.1 & 13 & 12.74 & 13.3 & 14.5 & 13.3 & 12.1 & 11.9 & 10.9 & 8.57 \\
\hline 8 & 10.2 & 12.5 & 15.2 & 14.7 & 13.34 & 13.6 & 14.5 & 13.9 & 13.6 & 14.4 & 14.1 & 11.6 \\
\hline 9 & 12.9 & 15 & 17.1 & 15.6 & 13.5 & 13.4 & 14.2 & 14 & 14.1 & 15.6 & 16.2 & 14 \\
\hline 10 & 14.6 & 15.4 & 17.7 & 16 & 13.51 & 13.1 & 14.1 & 13.8 & 14.1 & 16.2 & 16.7 & 14.6 \\
\hline 11 & 14.6 & 15.6 & 17.9 & 16.6 & 14.08 & 13.7 & 14.8 & 14.5 & 14.2 & 16.2 & 16.5 & 14.6 \\
\hline 12 & 14.1 & 15.3 & 17.8 & 17.2 & 14.81 & 14.3 & 15.6 & 15.2 & 14.4 & 16 & 16.2 & 14 \\
\hline 13 & 13.7 & 15.1 & 17.8 & 17.6 & 15.32 & 14.7 & 16.2 & 15.5 & 14.5 & 15.8 & 15.8 & 13.2 \\
\hline 14 & 13.6 & 14.9 & 16.8 & 16.8 & 14.72 & 13.6 & 15.3 & 14.4 & 13.9 & 15 & 15.2 & 12.8 \\
\hline 15 & 13.3 & 14.9 & 16.4 & 16.3 & 14.35 & 13.3 & 14.9 & 14.1 & 13.8 & 15.1 & 15.1 & 12.8 \\
\hline 16 & 12.7 & 14.8 & 16.2 & 16 & 13.97 & 13 & 14.4 & 13.8 & 13.6 & 14.9 & 14.6 & 12.4 \\
\hline 17 & 11.7 & 14.3 & 15.7 & 15.6 & 13.72 & 12.9 & 14.1 & 13.5 & 13.2 & 14 & 13.4 & 11.5 \\
\hline 18 & 11.5 & 13.5 & 14.8 & 15.1 & 13.59 & 12.5 & 13.7 & 12.9 & 12.7 & 13.3 & 11.9 & 10.6 \\
\hline 19 & 9.63 & 11.4 & 13.4 & 14 & 12.98 & 12.2 & 13.4 & 12.6 & 11.7 & 11.7 & 10.1 & 9.13 \\
\hline 20 & 7.96 & 9.51 & 12.1 & 12.9 & 12.34 & 11.8 & 13 & 12.1 & 10.8 & 10.2 & 8.84 & 8.01 \\
\hline 21 & 6.99 & 8.27 & 11.2 & 12.2 & 11.95 & 11.7 & 12.8 & 11.5 & 10.1 & 9.14 & 8.06 & 7.24 \\
\hline 22 & 6.56 & 7.72 & 10.7 & 11.9 & 11.94 & 11.6 & 12.8 & 10.8 & 9.68 & 8.95 & 7.64 & 6.8 \\
\hline 23 & 6.4 & 7.37 & 10.2 & 11.6 & 11.89 & 11.6 & 12.8 & 10.5 & 9.35 & 8.66 & 7.26 & 6.45 \\
\hline
\end{tabular}

In this project an analytical study for the gathered theoretical dataset of the two parameters has been conducted to examine the probability of getting a mutual correlation between the HPF \& OPMUF parameters.

In order to investigate the correlation between the selected parameters, the study has been made for two parts (periods of times). The first one was made for the monthly median values of the HPF and OPMUF parameters for the 24 hours of 12 months. 

Tehran)

Figure (3): shows a sample of the scatter plot between the HPF \& OPMUF values for the link (Baghdad-

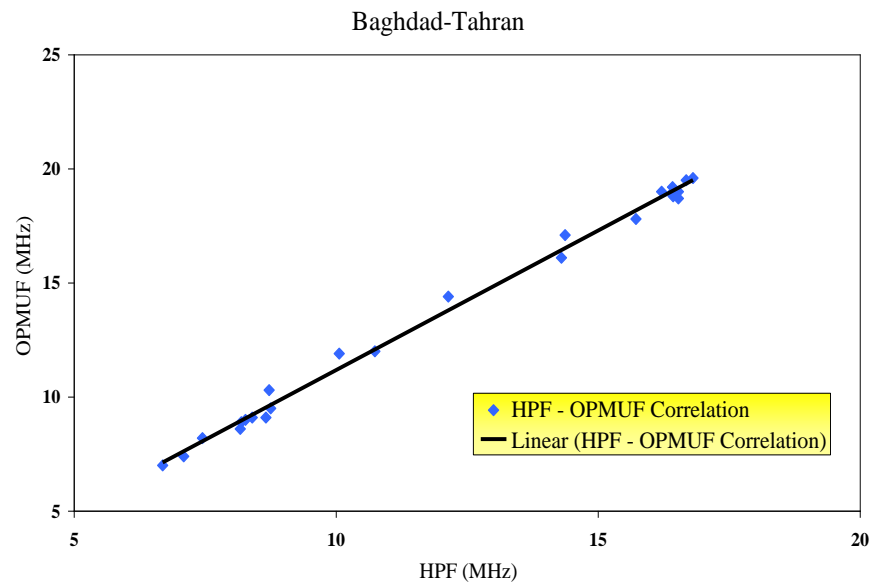

Fig. 3. Illustrates sample of monthly correlation between HPF\& OPMUF.

The second part was made to investigate the correlation between the two parameters between Baghdad and other receiving stations for the annual variation of all months of the year 2000. Figure (4) presents sample of the annual correlation for the link (Baghdad - Ar'ar).

Baghdad - Ar'ar

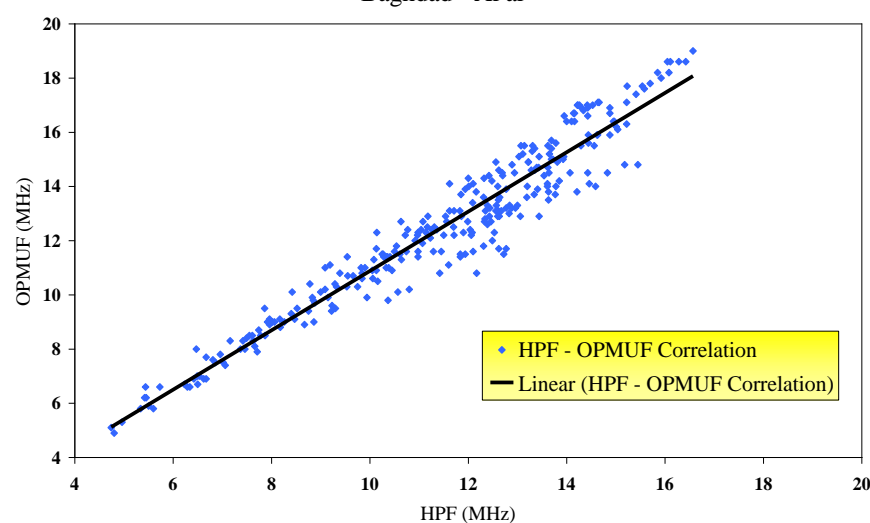

Fig. 4. Shows sample of the annual correlation between HPF \& OPMUF.

It's clear from the scatter plot of the monthly and annual behavior tests between (HPF \& OPMUF) parameters that shown in figures (3) \& (4), the correlation is simple and can be expressed as a linear regression correlation, so the suggested mutual correlation equation between the studied parameters can be presented by the following simple equation:-

$$
\text { OPMUF }=\sum_{n=0}^{n=1} a_{n}(H P F)^{n}
$$

Table (4) show samples of the coefficient values $\left(a_{0} \& a_{1}\right)$ that resulted from the analytical test of the monthly variation between the HPF and OPMUF parameters for 12 months and different links.

Table 4 Correlation coefficients for the monthly analytical test.

\begin{tabular}{|c|c|c|c|c|}
\hline \multicolumn{5}{|c|}{ Baghdad-Van } \\
\cline { 1 - 4 } Month & $\mathrm{a}_{\mathrm{o}}$ & $\mathrm{a}_{1}$ & $\mathrm{R}^{2}$ & MSE \\
\hline Jan & -0.3962 & 1.1417 & 0.9949 & \\
\hline Feb & -0.0471 & 1.1624 & 0.9907 & \\
\hline Mar & 0.8349 & 1.0357 & 0.9879 & \\
\hline Apr & 0.6696 & 1.0498 & 0.9766 & \\
\hline May & 1.0017 & 0.9746 & 0.9305 & \\
\hline Jun & 5.2328 & 0.5796 & 0.6365 & \multirow{2}{*}{0.2} \\
\hline Jul & 5.0213 & 0.5805 & 0.6142 & \\
\hline Aug & 4.0047 & 0.6797 & 0.8395 & \\
\hline Sep & 0.9789 & 1.0057 & 0.9826 & \\
\hline Oct & 0.4478 & 1.0336 & 0.9907 & \\
\cline { 1 - 4 } Nov & 0.7379 & 1.0616 & 0.9944 & \\
\cline { 1 - 3 } Dec & 0.0142 & 1.1553 & 0.9954 & \\
\hline
\end{tabular}




\begin{tabular}{|c|c|c|c|c|}
\hline \multicolumn{5}{|c|}{ Baghdad- Aleppo (Halab) } \\
\hline Month & $a_{o}$ & $\mathrm{a}_{1}$ & $\mathrm{R}^{2}$ & MSE \\
\hline Jan & -1.0692 & 1.1437 & 0.9978 & \multirow{12}{*}{0.19} \\
\hline Feb & -1.1176 & 1.2217 & 0.9939 & \\
\hline Mar & -1.2348 & 1.1833 & 0.9898 & \\
\hline Apr & -2.1006 & 1.2383 & 0.9752 & \\
\hline May & -1.9623 & 1.1894 & 0.903 & \\
\hline Jun & 2.9811 & 0.789 & 0.7638 & \\
\hline Jul & 2.4007 & 0.7952 & 0.7588 & \\
\hline Aug & 2.8833 & 0.7998 & 0.8851 & \\
\hline Sep & -1.4627 & 1.2061 & 0.9782 & \\
\hline Oct & -0.1433 & 1.0603 & 0.9901 & \\
\hline Nov & -0.7895 & 1.1991 & 0.9967 & \\
\hline Dec & -0.9311 & 1.2114 & 0.9938 & \\
\hline
\end{tabular}

\begin{tabular}{|c|c|c|c|c|}
\hline \multicolumn{5}{|c|}{ Baghdad- Tahran } \\
\hline Month & $\mathrm{a}_{\mathrm{o}}$ & $\mathrm{a}_{1}$ & $\mathrm{R}^{2}$ & MSE \\
\hline Jan & 0.8092 & 0.8815 & 0.9971 & \multirow{12}{*}{0.17} \\
\hline Feb & 0.9131 & 0.8136 & 0.9949 & \\
\hline Mar & 1.0532 & 0.8437 & 0.9881 & \\
\hline Apr & 1.5192 & 0.8156 & 0.9776 & \\
\hline May & 2.5331 & 0.7754 & 0.9245 & \\
\hline Jun & -0.9997 & 1.0619 & 0.7988 & \\
\hline Jul & -0.0973 & 1.0421 & 0.7726 & \\
\hline Aug & -2.0522 & 1.1405 & 0.9194 & \\
\hline Sep & 1.2731 & 0.8235 & 0.9838 & \\
\hline Oct & 0.3031 & 0.93 & 0.9953 & \\
\hline Nov & 0.6852 & 0.8328 & 0.9358 & \\
\hline Dec & 0.9709 & 0.808 & 0.9947 & \\
\hline
\end{tabular}

Samples of the predicted monthly values of the OPMUF parameter that have been calculated using the suggested formula (Predicted OPMUF) and the theoretical monthly values obtained from the execution of the international model (REC533) are presented in Figure (5) for different months and different sites.
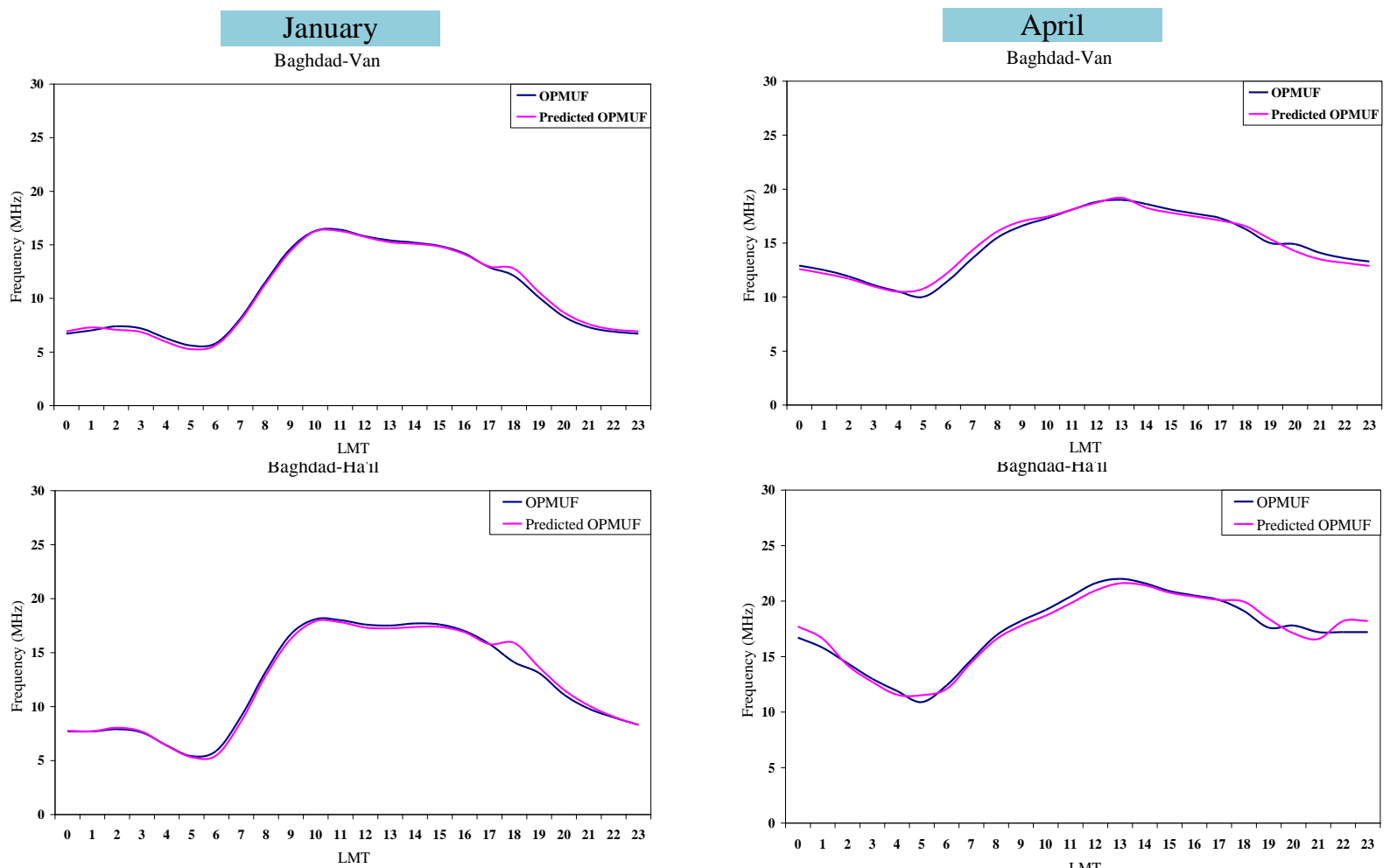

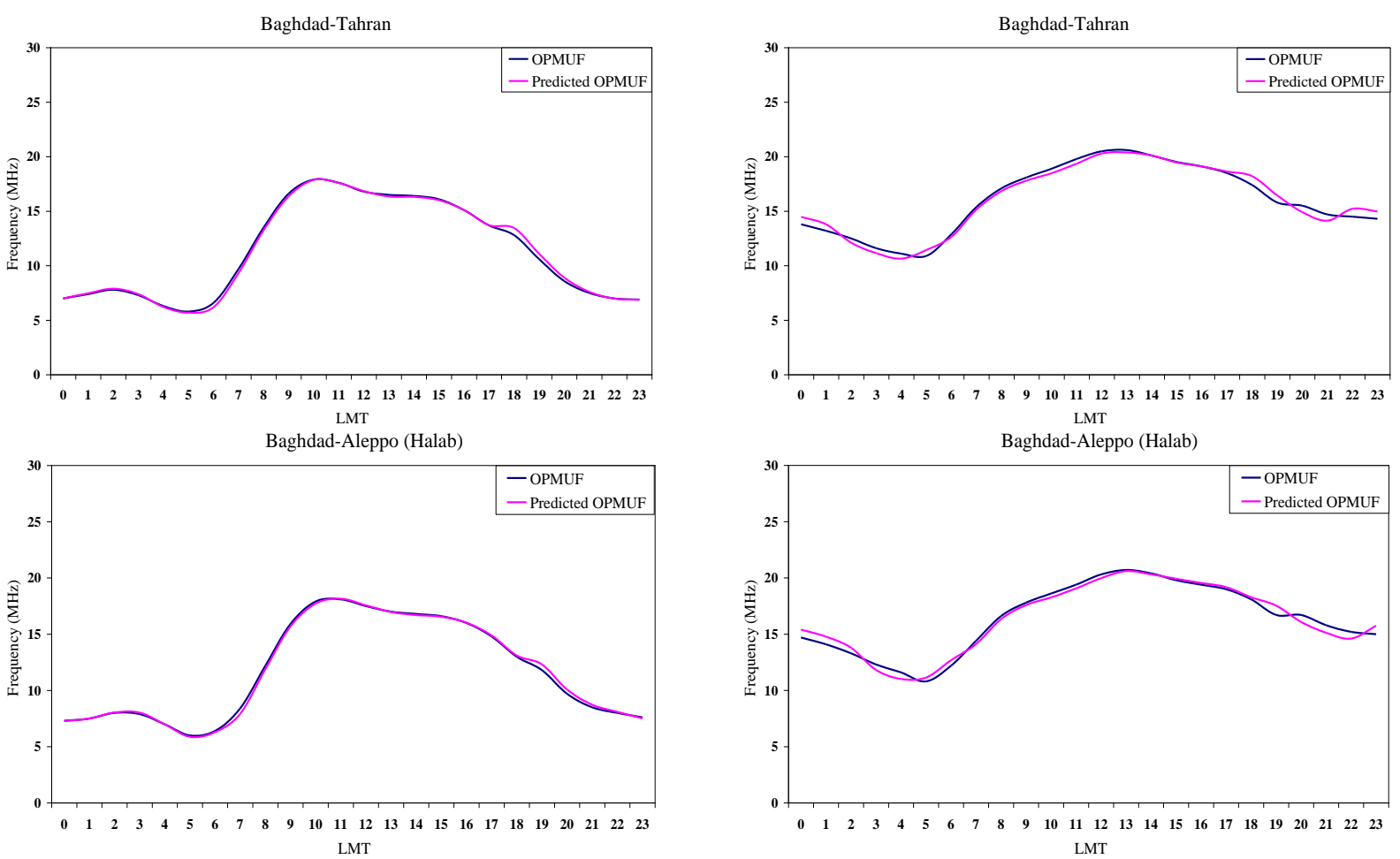

Baghdad-Aleppo (Halab)

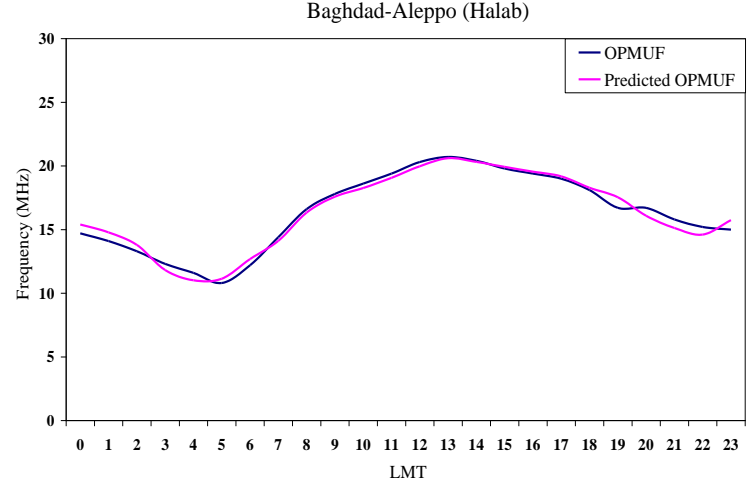

July

Baghdad-Van

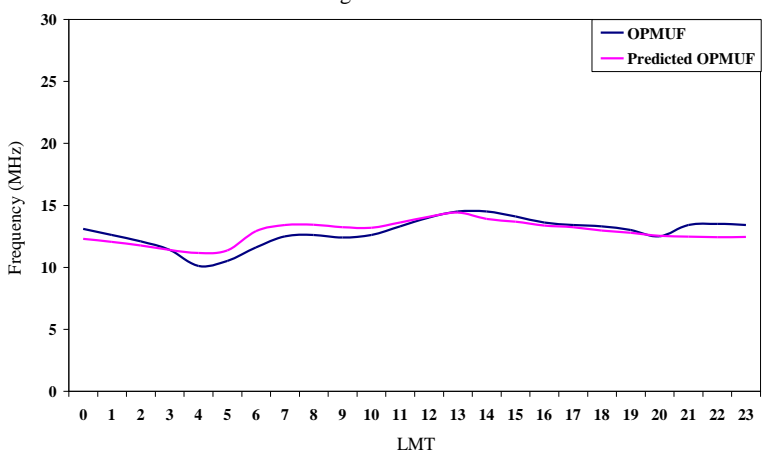

October

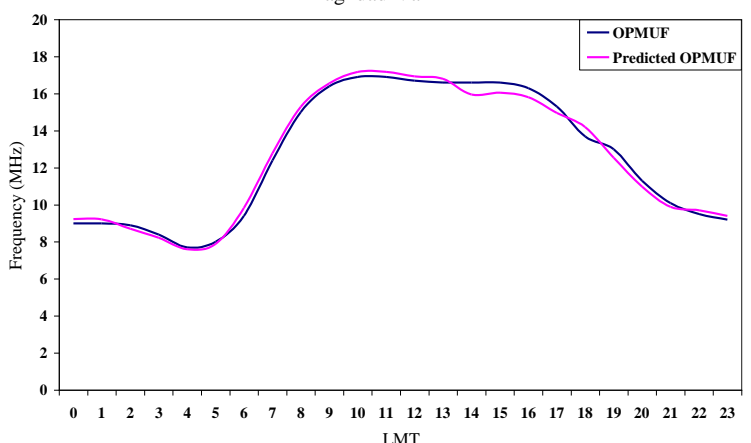

LMT

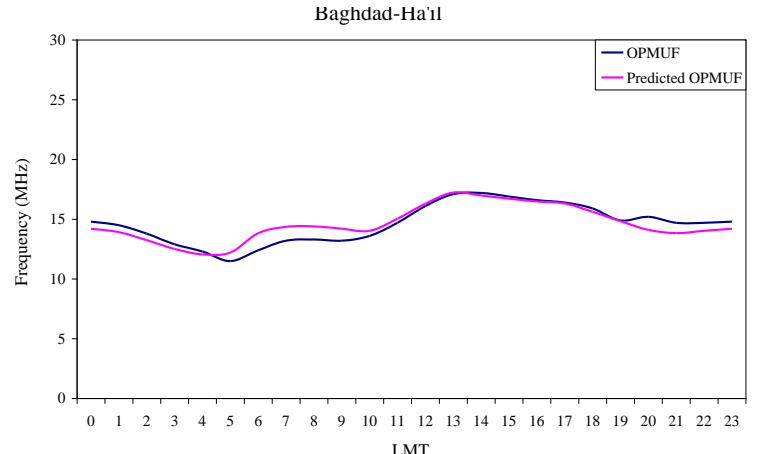

Baghdad-Ha'il

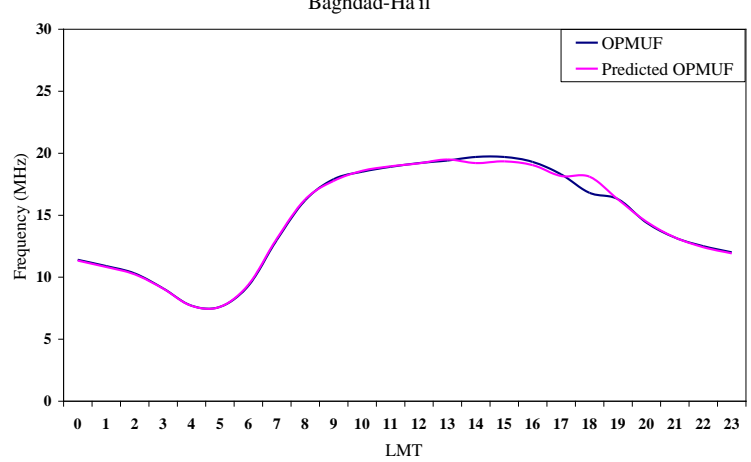

Baghdad-Tahran
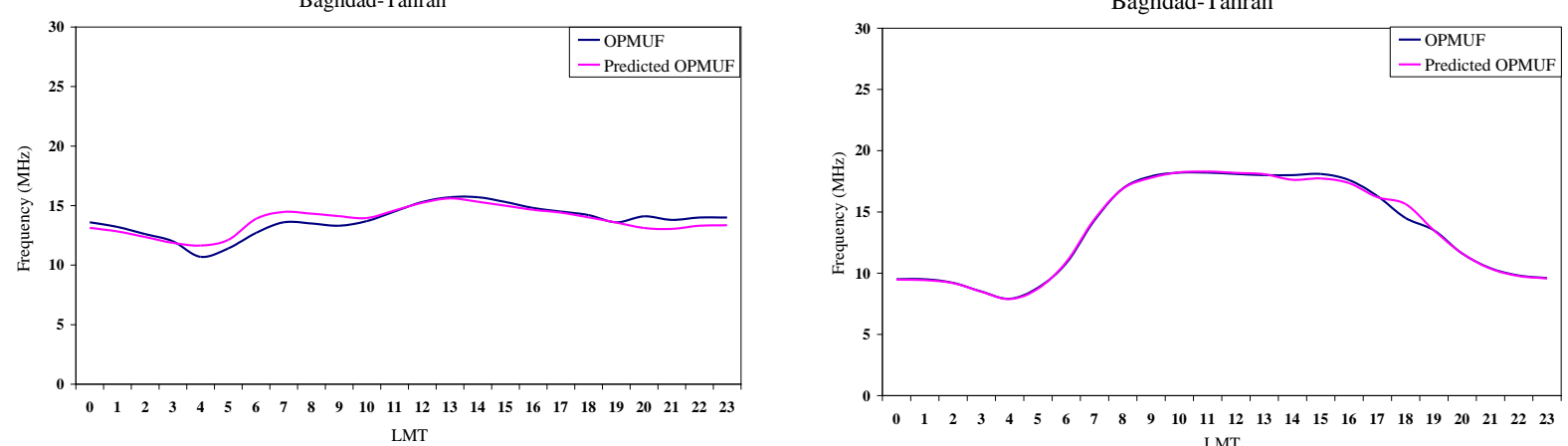

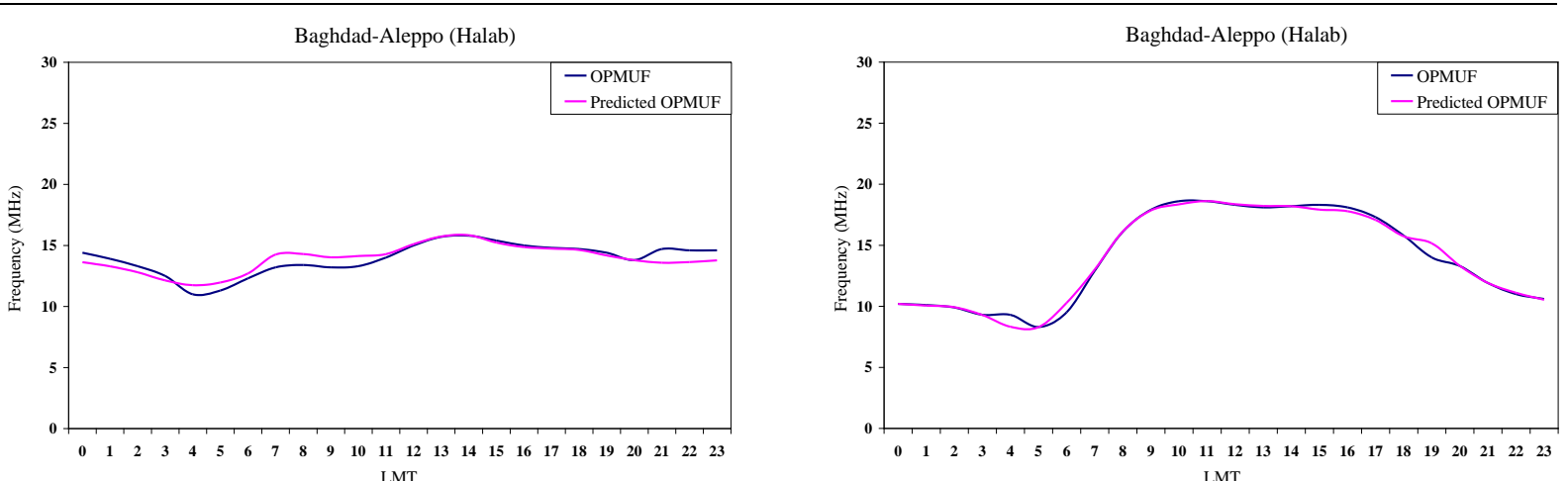

Fig. 5. Show samples of monthly theoretical \& predicted OPMUF.

Table (5) shows the annual correlation coefficients for the mean value of the annual variation between the HPF \& OPMUF parameters for the thirty five selected sites (receiving stations).

Table 5 Show annual correlated coefficients for the selected receiving locations.

\begin{tabular}{|l|c|c|c|}
\hline Station Name & $\mathbf{a}_{\mathbf{0}}$ & $\mathbf{a}_{\mathbf{1}}$ & $\mathbf{R}^{\mathbf{2}}$ \\
\hline Al-Abilah & -0.6865 & 1.1053 & 0.937 \\
\hline Al-Aqabah & -0.8511 & 1.1106 & 0.9327 \\
\hline Aleppo (Halab) & -0.5208 & 1.1058 & 0.9349 \\
\hline Al-Hazakah & -0.1409 & 1.0946 & 0.933 \\
\hline Al-Jawf & -0.2558 & 1.0976 & 0.9338 \\
\hline Al-Jufur & -0.2793 & 1.1003 & 0.9295 \\
\hline Al-Qatif & -0.7364 & 1.105 & 0.9373 \\
\hline Al-Raqqah & -0.3329 & 1.1054 & 0.9339 \\
\hline Amman & -0.6441 & 1.1083 & 0.9337 \\
\hline Ar'ar & -0.0686 & 1.0948 & 0.9348 \\
\hline Ba'ar & -0.6458 & 1.1114 & 0.9344 \\
\hline Buraydah & -0.5496 & 1.1046 & 0.9389 \\
\hline Dayr Alzawr & -0.0787 & 1.0927 & 0.9334 \\
\hline Demascuse & -0.5647 & 1.107 & 0.9341 \\
\hline Diyarbakir & 0.833 & 1.002 & 0.9195 \\
\hline Erzurum & 0.7473 & 1.0033 & 0.9225 \\
\hline Ha'il & -0.4437 & 1.1038 & 0.9377 \\
\hline Hamadan & -0.061 & 1.0938 & 0.9349 \\
\hline Hamah & -0.5432 & 1.1077 & 0.9353 \\
\hline Isfahan & -0.4176 & 1.1019 & 0.9402 \\
\hline Izmir & 0.3301 & 1.0248 & 0.917 \\
\hline Karmanshah & 0.1157 & 1.0803 & 0.9329 \\
\hline Kharma & -0.6889 & 1.105 & 0.9361 \\
\hline Kuwait & -0.3546 & 1.1044 & 0.94 \\
\hline Macca & -1.6073 & 1.1295 & 0.934 \\
\hline Mahabad & 1.0749 & 0.973 & 0.915 \\
\hline Malatya & 0.8571 & 0.9956 & 0.9204 \\
\hline Masjed Sul. & -0.1688 & 1.0973 & 0.9369 \\
\hline Riyadh & -0.8865 & 1.1105 & 0.9402 \\
\hline Shiraz & -0.6563 & 1.1051 & 0.9419 \\
\hline Tabriz & 0.8955 & 0.9976 & 0.9218 \\
\hline Tabuk & -0.8896 & 1.1164 & 0.9346 \\
\hline Tadmur & -0.3625 & 1.1064 & 0.9337 \\
\hline Tehran & -0.4619 & 1.103 & 0.9412 \\
\hline Tayma'a & -0.7875 & 1.1159 & 0.9364 \\
\hline Van & 0.8903 & 0.9976 & 0.9217 \\
\hline Zanjan & 0.9443 & 0.995 & 0.9221 \\
\hline & & & \\
\hline & & \\
\hline
\end{tabular}

Figure (6), show samples of the variation (fitting) between the calculated values of the annual predicted OPMUF that have been determined using the suggested formula and the annual theoretical OPMUF values that have been calculated using the REC533 international model. 

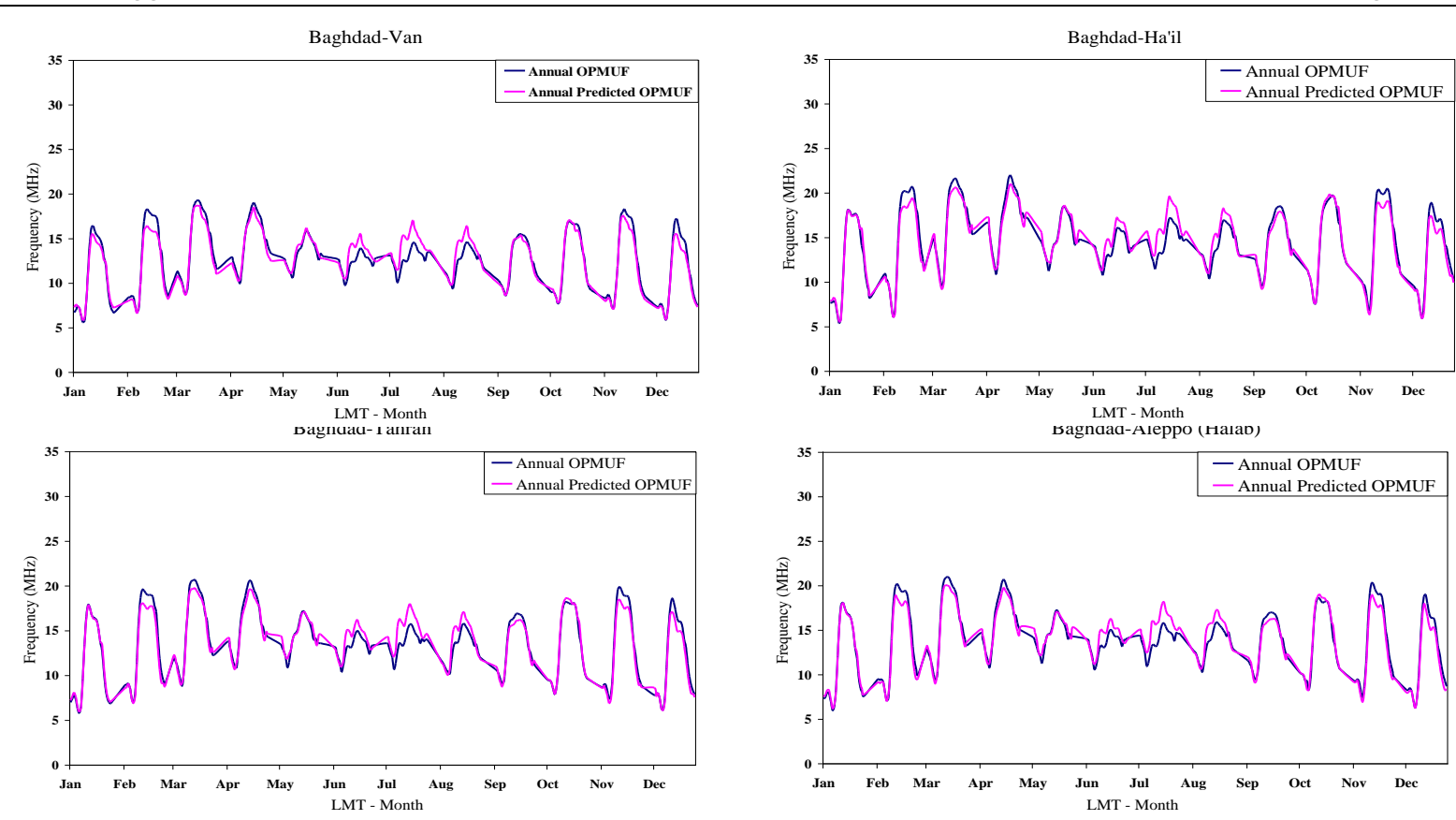

Fig. 6. Show samples of annual theoretical \& predicted OPMUF.

\section{Discussion \& Conclusions}

It's obvious form the analytical study that have been made for the dataset of the HPF and OPMUF parameters that the two parameters have the same behavior and consequently the correlation relationship can be conducted between them. The monthly and annual tests of the correlation between the two parameters "figures (3) \& (4)" show that the mutual correlation is simple and can be represented by a simple linear regression equation. The correlation coefficients that shown in tables (4), shows that the suggested equation can give a good fitting between the two parameters standing on the values of the $\left(\mathrm{R}^{2}\right)$ and the MSE which were within the accepted range. Figure (5), shows a monthly variation of the correlation between the theoretical and predicted OPMUF values for the months (January, April, July, and October) for the link (Baghdad - Van). The shapes show a good fitting between the two curves for the months (Jan., April, and Oct.) and a little variant in (July) that may due to the high solar activity during the summer time. Figure (6), shows an annual variation of the correlation between the theoretical and predicted OPMUF. The presented figures show that the correlation between the two parameters is good, so it gives generally mean square error (MSE) equal to (0.9102). According to the above discussion, we can conclude the following:

1. The behavior of the two parameters is the same, so the relationship is simple and the mutual correlation can be conducted.

2. The analytical study has been made for monthly and annual tests, in order to investigate the accurate correlation between the two parameters for different months and different directions to cover the studied region.

3. The suggested equation was simple (simple regression equation) gave a good results comparing with the theoretical data obtained from the execution of the two latest modern HF international communications models.

\section{References}

[1]. K. Rönmark, Lecture notes on space physics, Umeå Universitet, March 2003.

[2]. Kelley and Michael C., The Earth's Ionosphere: Plasma Physics and Electrodynamics, Academic Press, 1989.

[3]. J. Wang, X. Feng and L. Cheng, "Basic MUF observation and comparison of HF radio frequency prediction based on different ionosphere models", paper presented to International Symposium on IEEE Antennas Propagation and EM Theory (ISAPE), 2010. 403-406.

[4]. M.Warrington, N. Zaalov, J. Naylor \& A. Stocker, "HF propagation modeling within the polar ionosphere", RADIO SCIENCE, Vol. 47, RSOL13, 2012 , doi:10.1029/2011RS004909.

[5]. MIL-STD-188-141B, Interoperability and Performance standards for Medium and High Frequency Radio Systems, Department of Defense Interface Standard, Standardization Document Order Desk. PA 19111-5094. 700 Robbins Ave. Building 4D, Philadelphia, United States of America, March 1999.

[6]. K. Kavies, "Ionospheric Radio,” IEE Electromagnetic Waves series 31, Peter Peregrines Ltd., London, UK, 1989

[7]. Antenna Theory and Propagation, Department of the Army Military Auxiliary Radio System Fort Huachuca 85613-7070, USA, Ver. 1, May 2012.

[8]. ITU-R.- Rec. V.573-4, Radio communication vocabulary International Telecommunication Union, Switzerland, 2000.

[9]. L.R. Teters, J.L. Lloyd, G.W. Haydon and D.L. Lucas, Estimating the Performance of Telecommunication Systems Using the Ionospheric Transmission Channel, Institute for Telecommunication Sciences NTIA Report 83-127, July 1983.

[10]. ITU-RS Recommendation 533, High Frequency Propagation Model, NTIA/ITS, Boulder, Colorado 80305, USA, 1995. 